
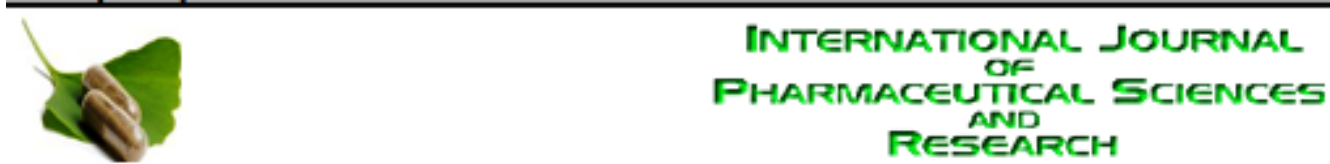

Received on 12 September, 2012; received in revised form, 20 November, 2012; accepted, 13 December, 2012

\title{
ANTIEMETICS: A REVIEW
}

Amit Kumar* ${ }^{1}$ and Anoop Kumar ${ }^{2}$

Jaipur College of Pharmacy ${ }^{1}$, affiliated to Rajasthan University of Health Sciences, Jaipur, Rajasthan, India University College of Medical Sciences ${ }^{2}$, affiliated to University of Delhi, Dilshad Garden, Delhi, India

Keywords:

Emesis, Nausea, Vomiting, CTZ, Cancer chemotherapy

Correspondence to Author:

Amit Kumar

Jaipur College of Pharmacy, affiliated to Rajasthan University of Health Sciences, Jaipur, Rajasthan, India

E-mail: amitruhs88@gmail.com

\begin{tabular}{|c|c|}
\hline QUICK RESPONSE CODE & \\
\hline & $\begin{array}{c}\text { IJPSR: } \\
\text { ICV : } 5.07\end{array}$ \\
\hline 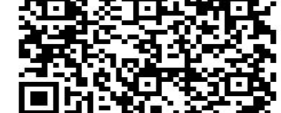 & $\begin{array}{c}\text { Website: } \\
\text { www.ijpsr.com }\end{array}$ \\
\hline
\end{tabular}

\section{ABSTRACT}

The act of emesis is controlled by the vomiting centre in the medulla, which integrates afferent input from the vestibular system, the chemoreceptor trigger zone (CTZ), the cortex and the gut. Nausea and vomiting induced by several cancer chemotherapy agents is often the most distressing side effect of treatment. The mechanism of action of antiemetic is related to blockage of various type of receptor located in various region of various organ of the body parts. Various drugs are classified under antiemetic like Ondansetron, Granisetron \& Metochlopramide etc. A critical review of the studies of aprepitant (a new NK1 receptor antagonist) and of palonosetron (a 5-HT3 receptor antagonist with a longer half-life) presented in this article. Aprepitant combined with dexamethasone and a 5-HT3 antagonist significantly increase the control of acute emesis with respect to dexamethasone. Palonosetron showed superior or similar efficacy to Ondansetron and dolasetron in patients submitted to moderately emetogenic chemotherapy Certain side effects arise due to excessive use of antiemetic like twitching, flushing of skin, headaches, tiredness, indigestion etc.

\section{INTRODUCTION:}

Emesis: It is a forcible emptying of gastric and occasionally intestinal contents due to stimulation of vomiting centre situated in medulla oblongata. The drug agents that provoke emesis are called emetic drugs e.g. apomorphine \& ipecacuanha. An individual has consumed certain toxic substances; it must be expelled before absorption by giving emetic drugs. If caustic substances have been ingested there is no need of inducing vomiting e.g. ammonia, chlorine bleach, dye, toilet cleaners, or battery acid. Activated charcoal is given when emesis is due to $\mathrm{Cl}$.

Antiemetics: The drug agents that antagonize the action of emetics are called antiemetic drugs. Cisplatin provides an exacting test for anti emetics. This agent at high doses is universally emetic (if anti-emetics are not given) and patients usually experience five or more emetic episodes.

IPECAC: It stimulates the CTZ in the medulla \& acts directly on the gastric mucosa. Take water (not milk or carbonation) if injested, its onset of action occur in 15 to 30 min. Its toxicity can be cured by giving charcoal. The toxicity indications of ipecac are hypotension, tachycardia, chest pain, diarrhea, sedation, lethargy etc 1,2 .

CINV (Chemotherepy induced Nausea and Vomiting) Clasification: There are clinically 5 distinct forms of Chemotherapy Induced Nausea and Vomiting (CINV): acute, delayed, anticipatory, break through and refractory. 
Acute: Acute nausea and vomiting typically occurs within the first 24 hours after chemotherapy administration, it can be for 1 or 2 hours after the start of chemotherapy and last for a number of hours. Cyclophosphamide and carboplatin are chemotherapy agents may cause acute CINV that begins 8 to 10 hours after administration. Antiemetic agents given before chemotherapy can lower the incidence of severe acute CINV. The essential tool for managing acute CINV is prevention, which is more effective than the treatment 3,6 .

Delayed: Delayed nausea and vomiting has been defined as CINV that occurs within 24 hours after chemotherapy administration. In some cases it has been observed that delayed CINV may begin as early as 16 hours after chemotherapy administration. Delayed CINV can cause significant nutrition and hydration problems but it is less severe than acute CINV and patients may require intravenous fluid replacement or even hospitalization ${ }^{3,6}$.

Anticipatory: Anticipatory CINV is a conditioned response and can occur before, during, or after the administration of chemotherapy. Several environmental stimuli, such as tastes, sensations, smells sights, or psychological factors also associated with the chemotherapy experience. Manifestations of anticipatory emesis can range from mild to severe. Treatments for anticipatory CINV include the use of antianxiety medications and behavioural interventions such as guided imagery, hypnosis, and thermal bio feedback ${ }^{3,6}$.

Break Through: In this vomiting occurs despite prophylactic antiemetic treatment and requires rescue with antiemetic agents ${ }^{3}$.

Refrectory: In this, vomiting that occurs during subsequent treatment cycles in cases where antiemetic prophylaxis and/or rescue have failed in prior cycles ${ }^{3}$.

Pathophysiology of Emesis: Pathophysiology of emesis is controlled by neurophysiologic mechanisms. Nausea and vomiting are mediate through the central nervous system (CNS) such as the stimulation of a complex reflex mediated by the "vomiting centre" in the brain stem, which integrates afferent stimulation from a number of neurologic pathways.
Vomiting is a fundamental protective reflex to prevent the harmful effects of ingested potentially toxic substances. The most common mechanism of CINV is activation of the chemoreceptor trigger zone (CTZ) by chemotherapy agents. Neurotransmitters such as dopamine, acetylcholine, histamine, opiates, serotonin, and substance $\mathrm{P}$ act on their corresponding receptors and initiate emesis after chemotherapy administration (Figure 1). These neurotransmitters are released from cells that are susceptible to the presence of toxic substances in the blood or cerebrospinal fluid.

Dopamine is the neurotransmitter that appeared to be most responsible for CINV. The release of serotonin activates receptors of the $5-\mathrm{HT}_{3}$ type, which stimulate the CNS centres mediating the emetic response. Although serotonin plays an important role in the acute phase of CINV, it is a less significant mediator of delayed emesis. Substance $P$ is a neuropeptide found in the CTZ and gastrointestinal tract, where it is localized with serotonin in the enterochromaffin cells. Its potential emetic effects result from binding to the NK1 receptor. Substance $P$ levels in the peripheral circulation may become elevated after administration of cisplatin ${ }^{4,5,6}$.

Mechanism of Nausea and Vomiting: The mechanism of nausea and vomiting associated with activation of various receptors located in different parts of the body. It include the following ${ }^{4,7}$ :

- Stimulation of chemoreceptor trigger zone of the area postrema

- Peripheral mechanisms

- Damage of GI mucosa

- Stimulation of GI neurotransmitter receptors

- Cortical mechanisms

- Direct cerebral activation

- Indirect (psychogenic) mechanisms

- Vestibular mechanisms: By activation of vestibular apparatus

- Alteration of taste and smell. 


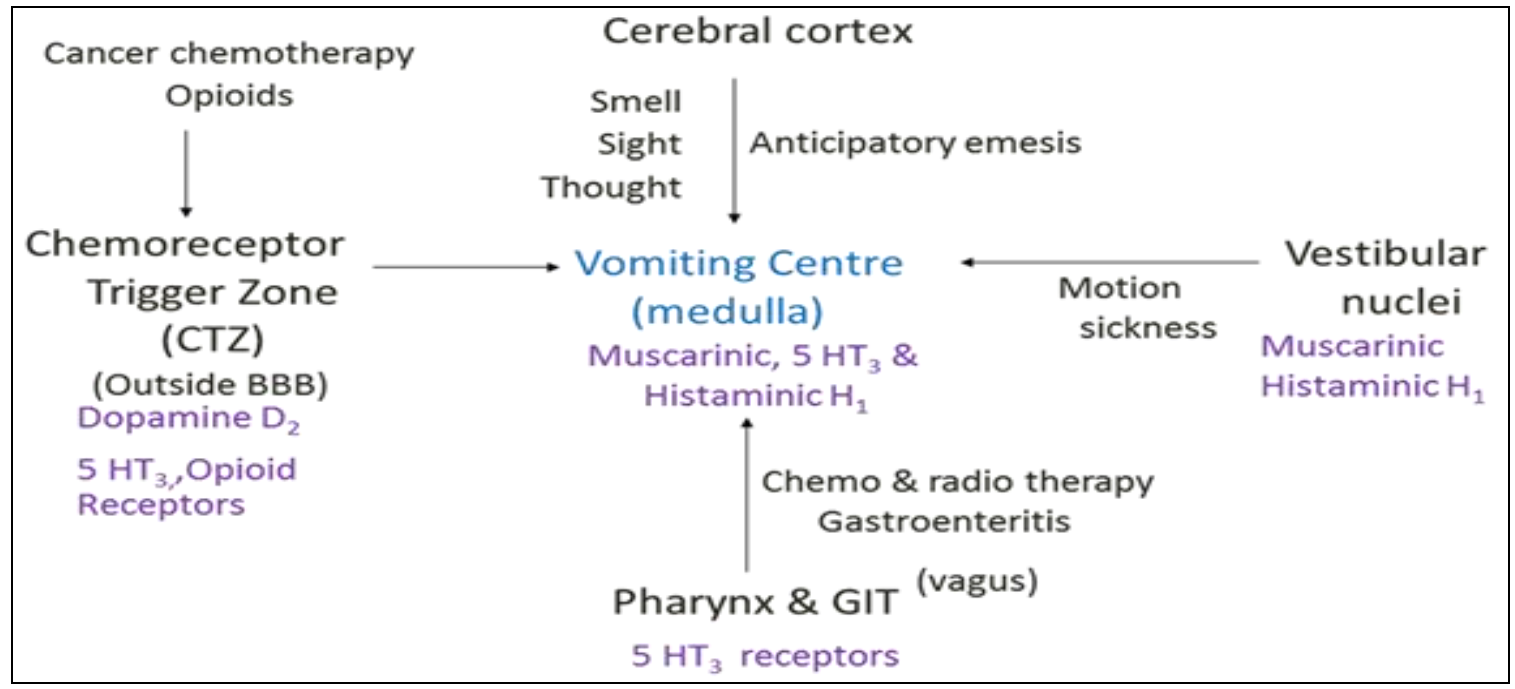

FIGURE 1: PATHOPHYSIOLOGY OF EMESIS

Indications of Vomiting: There are certain indications of vomiting associated to various reasons. Some of them are listed below ${ }^{8}$ :

a) Chemotherapy induced nausea and vomiting (CINV)

b) Post irradiation vomiting

c) Post operative vomiting

d) Vomiting of pregnancy

e) Motion sickness

Antiemetic Action: The key components areas in the hindbrain and the abdominal vagal afferents have been identified. The locations of neurons that coordinate the body functions associated with emesis are spread throughout the medulla, supporting the notion that a central pattern generator coordinates the sequence of behaviours during emesis. The central pattern generator receives indirect input from both the

(i) area postrema [chemoreceptor trigger zone (CTZ)] and;

(ii) abdominal vagus by means of the nucleus tractus solitarius.

CTZ: CTZ is located in the area postrema at the bottom end of the fourth ventricle. The CTZ is a circumventricular organ, this structure lacks an effective blood-brain barrier and so it is able to detect emetic agents in both the systemic circulation and the cerebrospinal fluid. The antiemetic action is achieved by antagonising the action of various receptors located in these areas (Figure 2). The area postrema has afferent and efferent connections with underlying structures, the sub nucleus gelatinous and nucleus tractus solitarius, receiving vagal afferent fibres from the gastrointestinal tract ${ }^{9}$.

Abdominal Vagal Afferents: The abdominal vagal afferents appear to have the greatest relevance for CINV. On the terminal ends of the vagal afferents, a variety of receptors such as 5-hydroxytryptamine 3 (5HT3), neurokinin-1 and cholecystokinin-1, are located. Serotonin $(5-\mathrm{HT})$ is released from enterochromaffine cells in the small intestinal mucosa due to exposure to radiation or cytotoxic drugs, which are adjacent to the vagal afferent neurones on which 5 - $\mathrm{HT} 3$ receptors are located.

Vagal afferent neurones activated by the released serotonin via the $5-\mathrm{HT} 3$ receptors that ultimately leads to an emetic response mediated via CTZ within the area postrema. Although the vagal nerve relays information to the area postrema, most of the sensory information from the vagal nerve is relayed to the tractus solitarius further interacting with the central pattern generator. Substance $P$ is a neuropeptide that acts as a neurotransmitter or neuromodulator within both the central and peripheral nervous system by preferentially binding to the NK-1 receptor. Neurokinin 1 receptor antagonists inhibit action of substance $P$ in the emetic pathways in both the central and peripheral nervous systems ${ }^{9,10}$. 


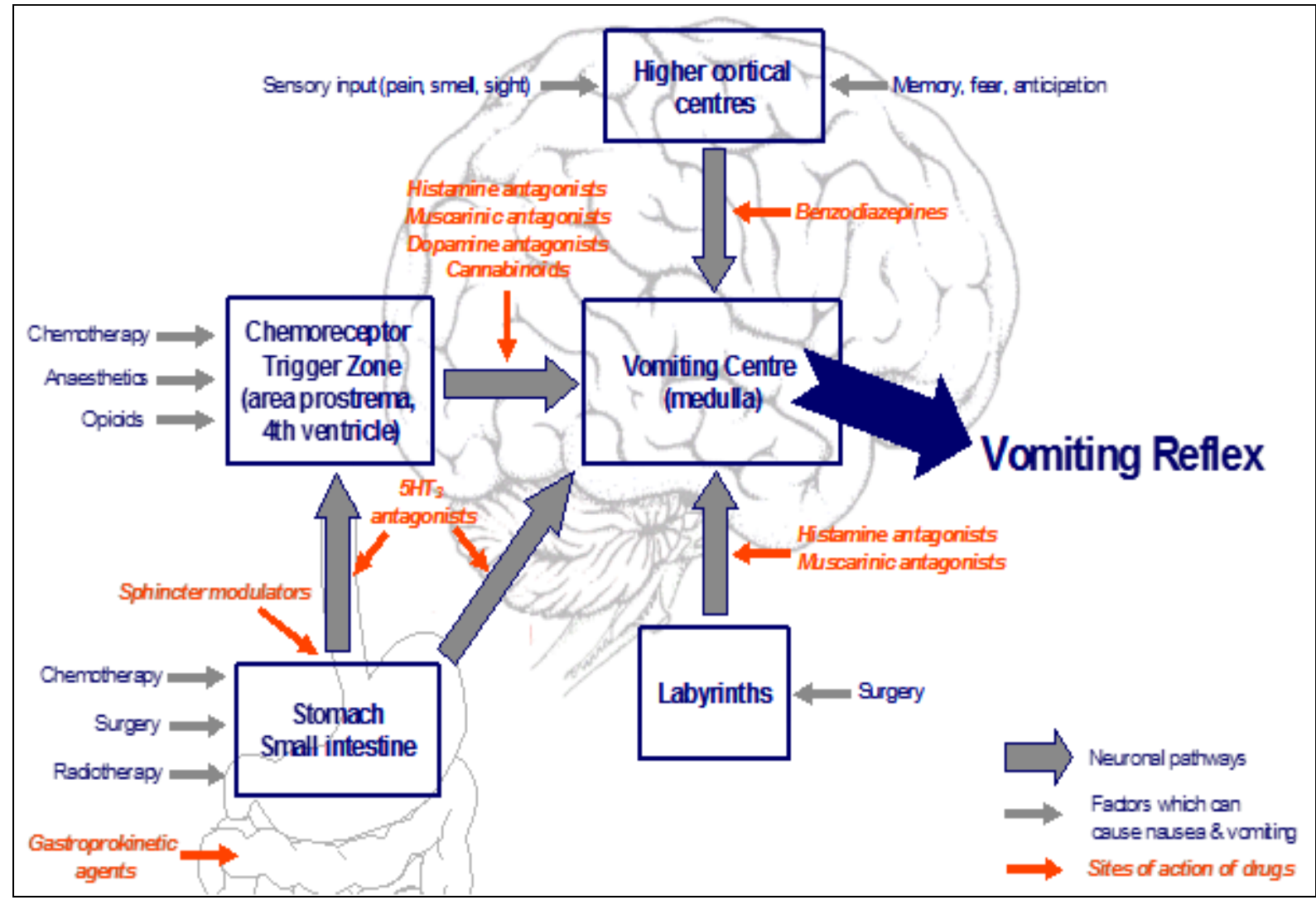

FIGURE 2: ACTION OF ANTIEMETIC DRUGS AT VARIOUS ZONES OR RECEPTORS OF THE BODY

Classification of Antiemetics ${ }^{1}$ : The antiemetic drugs are classified into the following categories:

1. Anticholinergics: Hyoscin, Dicyclomine

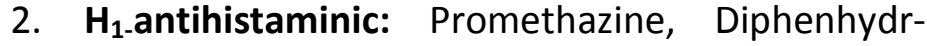
amine, Doxylamine, Cyclizine

3. Neuroleptics: Chlorpromazine, Prochlorperazine, Haloperidol

4. Prokinetic drugs: Metochlopramide, Domperidone, Cisapride, Mosapride, Tegaserod.

5. 5-HT $\mathbf{H}_{3}$ antagonists: Ondansetron, Granisetron.

6. Adjuvant antiemetic: Dexamathasone, Benzodiazepines, Cannabinoids.

Anticholinergic ${ }^{1,8,11}$ : Among all muscarinic receptors only M3 and M5 receptors may be responsible for the beneficial effect of anticholinergics.

\section{Mechanism of action:}

- Anticholinergic medications act on muscarinic receptors and increase motion tolerance.
- These block the conduction of nerve impulses across a cholinergic.

- All visceral smooth muscles that receive motor innervations are relaxed by these.

- Tone and amplitude of contraction of stomach and intestine are reduced.

- Also produce sedative effect.

Use: It is used in the prevention or treatment of motion sickness.

Adverse effects: Sedation, dizziness, confusion, dry mouth, cycloplegia and urinary retention.

Types of Cholinergic Agents: There are two types of cholinergic agents:
A) Direct cholinergic agents
B) Indirect cholinergic agents

A. Direct cholinergic agents: It Stimulate cholinergic receptors in the wall of the GIT. 
1) Acetylcholine: It is not used pharmacologically because:

a) It affects both nicotinic and muscarinic receptors

b) It is degraded rapidly by acetyl cholinesterase.

2) Bethanechol:

a) Muscarinic receptor agonist

b) Resists enzymatic hydrolysis.

c) In addition, it lacks real prokinetic efficacy,

A) Indirect cholinergic agents:

Acetyl cholinesterase Inhibitors. These drugs inhibit the degradation of $\mathrm{ACh}$, allowing $\mathrm{ACh}$ to accumulate at sites of release. Neostigmine has been used to treat paralytic ileus.

Antihistaminics ${ }^{1,11}$ :

Mechanism of action: These are $\mathrm{H}_{1}$ receptor blockers and their action is anti allergic type.

- Also used for nonproductive cough, allergy symptoms, sedation.

- They block the extra pyramidal side effect of metoclopramide while supplementing its antiemetic action.

Use: Antihistaminic agents are used in the prevention or treatment of motion sickness.

Adverse effects: Sedation, dizziness, confusion, dry mouth, cycloplegia, and urinary retention.

Neuroleptics $^{1,4}$ :

Mechanism of action: Neuroleptic drugs exert sedatives and atiemetic effect. It includes butyrophenones which act peripherally on the gastrointestinal tract and block dopamine receptors in the CTZ. Histamine receptors do not affect by droperidol and therefore it is not effective for motion sickness but it inhibit the activation of aminobutyric acid, serotonin, norepinephrine and neuronal nicotinic acetylcholine receptors.
It also exhibits mild peripheral- adrenoreceptor antagonism. Certain indications for Droperidol are observed such as sedation in patients with chronic obstructive pulmonary disease and decrease of blood pressure. Action of neuroleptic is facsilated by several DA-ergic systems or pathways, recognized in the brain:

1) Mesolimbic-mesocortical pathway: The first pathway (the one most closely related to behavior) is projects from cell bodies near the substantia nigra to the limbic system and neocortex (Figure 3).

2) Nigrostriatal pathway: The second system consists of neurons that project from the substantia nigra to the caudate and putamen; it is involved in the coordination of voluntary movement (Figure 3 ).

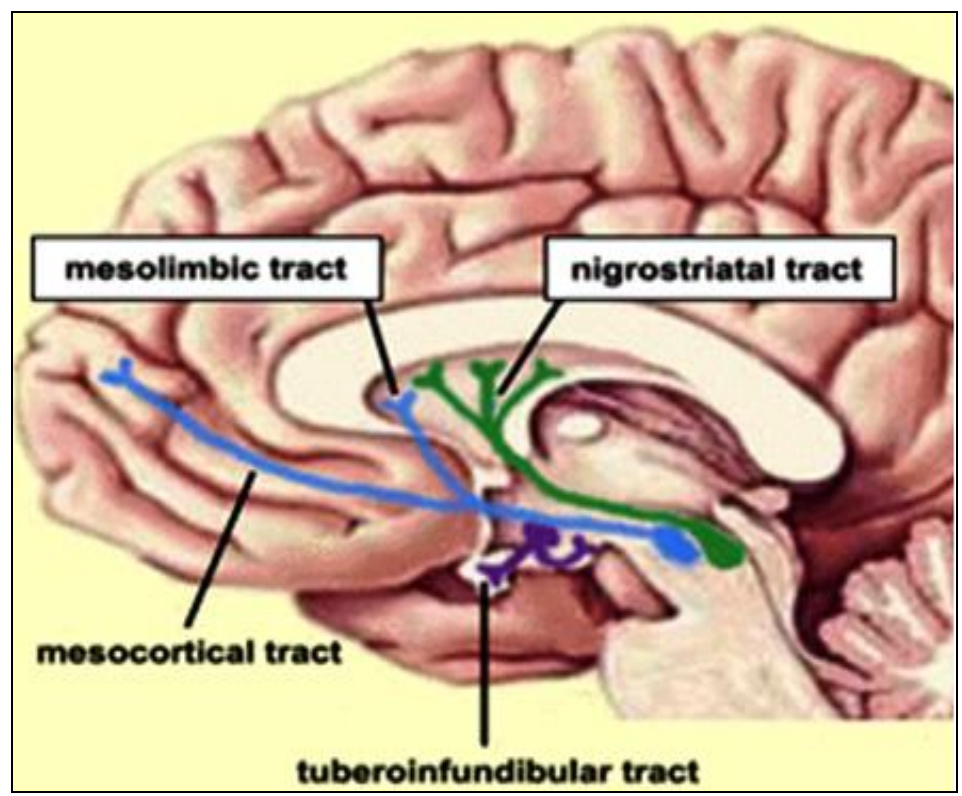

FIGURE 3: DA-ERGIC SYSTEMS OR PATHWAYS IN THE BRAIN

3) Tuberoinfundibular system: The third pathway connects arcuate nuclei and periventricular neurons to the hypothalamus and posterior pituitary. DA released by these neurons physiologically inhibits prolactin secretion (Figure 3).

4) Medullary-periventricular pathway: The fourth DA-ergic system consists of neurons in the motor nucleus of the vagus whose projections are not well defined. This system may be involved in eating behavior (Figure 3). 
Five DA receptors have been described, consisting of two separate families - The $D_{1}$ and $D_{2}$ receptors.

1. The $D_{1}$ receptor is coded by a gene on chromosome 5 , increases cAMP by Gs-coupled activation of adenylyl cyclase, and is located mainly in the putamen, nucleus accumbens, and olfactory tubercle. The second member of this family, $D_{5}$, is coded by a gene on chromosome 4 , also increases cAMP. The therapeutic potency of antipsychotic drugs does not correlate with their affinity for binding the $D_{1}$ receptor, but for most, correlates strongly with $D_{2}$ affinity.

2. The $D_{2} \& D_{3}$ receptor are coded on chromosome 11, decreases CAMP (by G-coupled inhibition of adenylyl cyclase) and $D_{2}$ inhibits calcium channels but opens potassium channels. It is found on both pre and postsynaptically on neurons in the caudate-putamen, nucleus accumbens, and olfactory tubercle. $D_{3}$ receptor located in the frontal cortex, medulla and midbrain. $D_{4}$ receptor also decreases cAMP.

\section{Prokinetics $^{1,12}$}

\section{Metoclopramide:}

Pharmacological action: Metoclopramide enhance coordinated GIT propulsive motility of the upper digestive tract where it increases lower esophageal sphincter tone and stimulates antral and small intestinal contractions. Metoclopramide has no clinically significant effects on motility of the colon.

Mechanisms of action: Metoclopramide on GIT acts by
a) Dopamine receptor antagonism
b) $5-\mathrm{HT}_{4}$-receptor agonism
c) Vagal and central $5-\mathrm{HT}_{3}$-antagonism
d) Sensitization of muscarinic receptors on smooth muscle
e) Antiemetic action

Therapeutic Use: There are several therapeutic uses regarding Metoclopramide as listed below:
- It is used in nausea and vomiting that often accompanies GI dysmotility syndromes.

- It is prescribed in Gastro esophageal reflux disease (symptomatic relief but not healing of esophagitis).

- It is also prescribed in Gastro paresis where it improves gastric emptying.

- Used in diagnostic procedures such as intestinal intubation or contrast radiography of the GI tract.

- Metoclopramide also used in Postoperative ileus

Administration: Metoclopramide administered by various routes as given below

1) Oral (rapid absorption)

2) I.M. in cases of nausea and vomiting

3) I.V. infusion in chemotherapy-induced vomiting

\section{Adverse Effects:}

- Extra pyramidal effects occur more commonly in children and young adults at higher dose.

- Tardive dyskinesia - Repetitive, involuntary, purposeless movements (usually involve the face) like tongue protrusion, lip smacking, pursing of the lips and rapid eye blinking. It occurs with chronic treatment (months to years) and may be irreversible.

- Akathisia - Restlessness and inability to sit still or remain motionless.

- Dystonias - Muscular spasms of neck usually occurring acutely after intravenous administration

- Parkinsonian like symptoms that may occur several weeks after initiation of therapy generally respond to treatment with anticholinergic or antihistaminic drugs and are reversible upon discontinuation of metoclopramide.

- Galactorrhea by blocking the inhibitory effect of dopamine on prolactin release. 


\section{Domperidone:}

Pharmacological actions: It enhance coordinated GIT propulsive motility of the upper digestive tract where it increases lower esophageal sphincter tone and stimulates antral and small intestinal contractions. It has no clinically significant effects on motility of the colon.

Mechanism of action: It acts on dopamine $D_{2}$ receptor in CTZ which is outside BBB.

\section{Adverse effects:}

- No extra pyramidal side effects because it can not cross the blood-brain barrier.

- Galactorrhea-By inhibiting dopamine-mediated inhibition of the release of prolactin as the pituitary lacks blood-brain barrier.

\section{Serotonin Antagonists ${ }^{1,6,8,13}$ :}

Mechanism of action: The action of serotonin antagonists is facilitated by blockade of receptors or physiological paths:

- Block serotonin receptors in the GI tract, CTZ, and VC

- Peripheral 5-HT3 receptor blockade on intestinal vagal afferents.

- Central 5-HT3 receptor blockade in the vomiting center and chemoreceptor trigger zone.

- Ondansetron block the depolarising action on vagal afferents

- Ondansetron blocks emetogenic impulses both at their peripheral origin and their central relay.

- Ondansetron does not block dopamine receptors.

- Granisetron is $10-15$ more potent than ondansetron.

- Emesis mediated by vagal stimulation (e.g. postoperative and chemotherapy)
Excretion: Serotonin antagonists get excreted out by liver \& kidney. There is no need of dose reduction in renal insufficiency but needed in hepatic insufficiency.

Adverse Effects: The most common adverse effects are:

- Headache and dizziness

- Constipation or diarrhea

\section{Benzodiazepines ${ }^{1,13}$ :}

Mechanism of action: When GABA binds with the $\mathrm{GABA}_{\mathrm{A}}$-receptor (Figure 4 a $\boldsymbol{\&} \mathbf{b}$ ), the permeability of the central pore of the receptor to chloride ions increases, allowing more ions into the neuron and decreasing excitability. Classical benzodiazepines in clinical use enhance the effectiveness of GABA by lowering the concentration of GABA required for opening the channel. These drugs are agonists at the receptor and the flumazenil (antagonist) prevents agonists from binding at the receptor site.

Gamma amino butyric acid (GABA) is probably the most important inhibitory transmitter in the CNS. GABA-ergic neurons are distributed widely in the CNS. GABA controls the state of excitability in all brain areas and the balance between excitatory inputs (mostly glutamatergic) and the inhibitory GABA-ergic activity. If the balances wings in favor of GABA, then sedation, amnesia, muscle relaxation and ataxia appear and nervousness and anxiety are reduced.

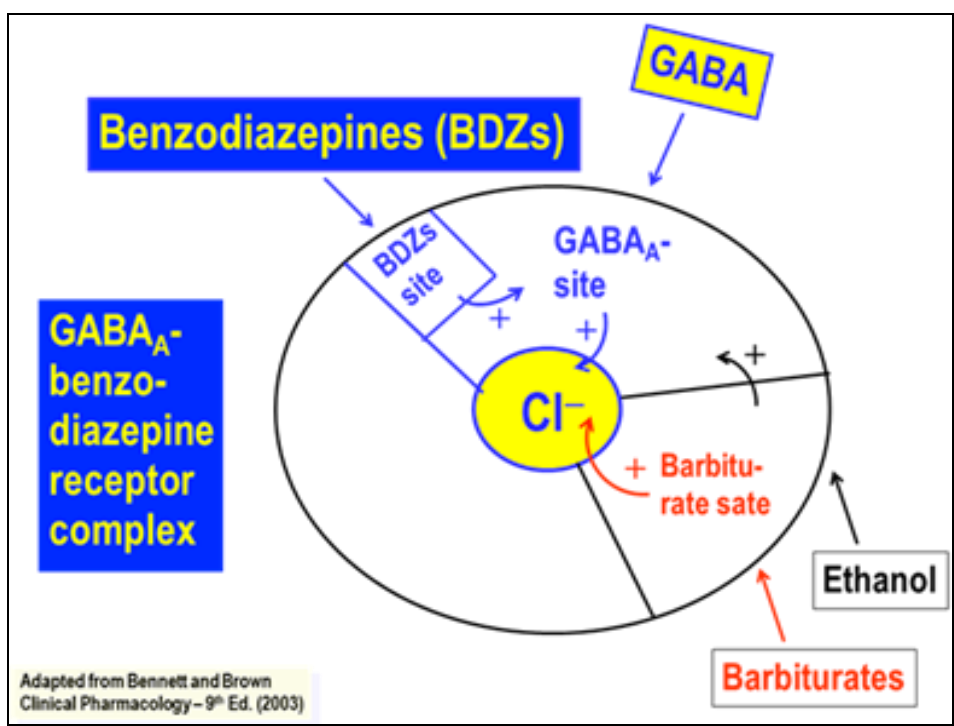

FIGURE 4(A): BENZODIAZEPINES-GABA RECEPTOR COMPLEX (UPPER VIEW) 


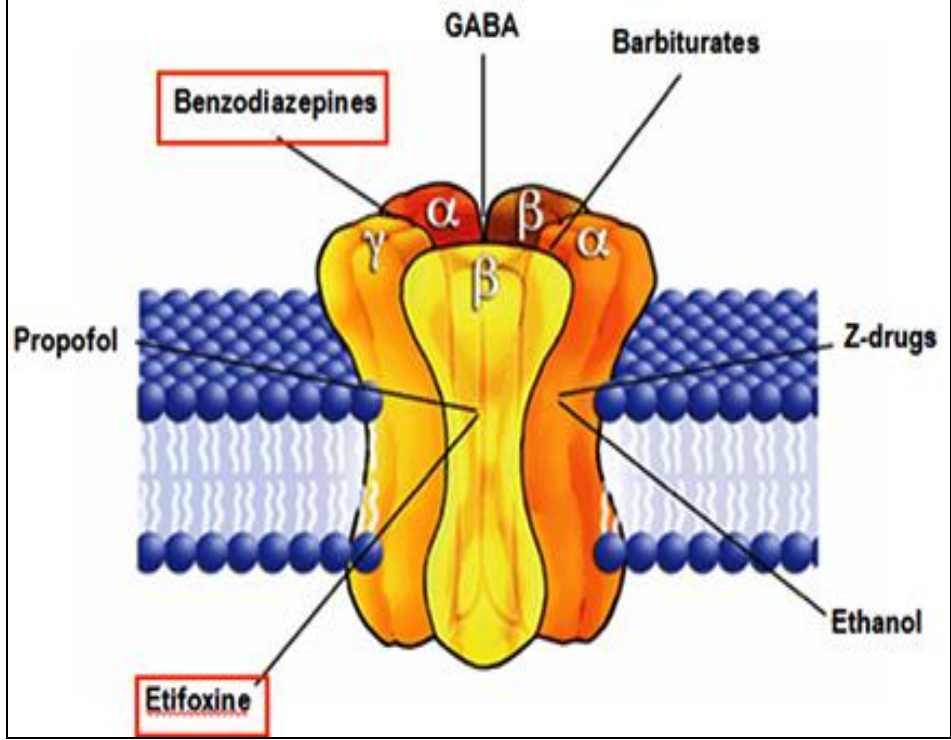

FIGURE 4(B): BENZODIAZEPINES-GABA RECEPTOR COMPLEX (SIDE VIEW)

Uses: Benzodiazepines such as diazepam are used prior to the initiation of chemotherapy to reduce anticipatory vomiting or vomiting caused by anxiety.

\section{Corticosteroids ${ }^{1,13}$ :}

Mechanism of action: It acts possibly by suppressing peritumoral inflammation and prostaglandin production. Corticosteroids also have antiemetic action e.g. Dexamethasone and methylprednisolone have a high therapeutic index when used to prevent chemotherapy-induced emesis. When corticosteroids are administered with the moderate cytochrome P-450 3A4 inhibitor aprepitant, doses should be reduced by approximately $50 \%$.

Use: It enhance efficacy of 5HT3 receptor antagonists in the treatment of chemotherapy-induced vomiting

\section{Cannabinoids ${ }^{1,14}$ :}

Mechanism of action: $\Delta^{9}$-tetrahydrocannabinol is the constituent of cannabis that is responsible for the pharmacologic action. It is also expressed as THC. The antiemtic action of cannabinoids is mediated by two types of receptors, $\mathrm{CB}_{1}$ and $\mathrm{CB}_{2}$ (Howlett, 1995). Both are G-protein-coupled receptors found in membranes of nerve cells. On chromosomes 6 and 1 physical and genetic localization of cannabinoid receptor genes $\mathrm{CNR}_{1}$ and $\mathrm{CNR}_{2}$ have been mapped respectively. In the CNS, CB1 receptor is expressed in the neurons and the $\mathrm{CB}_{2}$ receptor is often localized in lymphoid tissues in the periphery. Cannabinoid $\mathrm{CB}_{1}$ receptors are located predominantly in the central nervous system such as NTS (Nucleus Tractus Solitarius), Nodose Ganglion, Myentric Plexus and Submucosal Plexus (Figure: 5). So they constitute the only type of cannabinoid receptor expressed in the brain, where they are extraordinarily abundant. A number of selective $\mathrm{CB}_{1}$ agonists (e.g. methanandamide, O-1812) and antagonists (e.g. SR141716A, AM251, and AM281) have been synthesized in more recent years. Selective $C_{2}$ agonists (e.g. JWH133, AM1241) and antagonists (e.g. SR144528, AM630) have also been discovered.

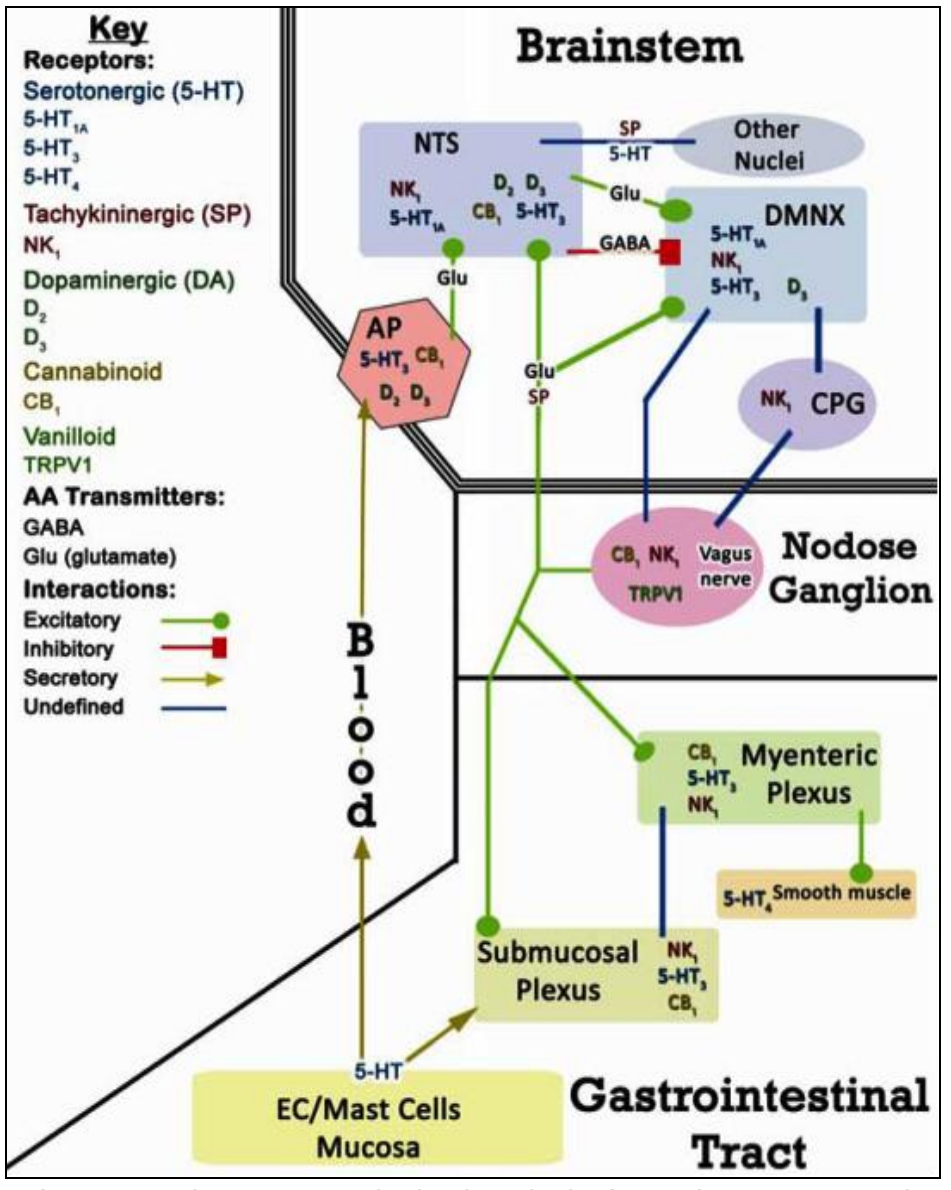

FIGURE 5: CINV EMETIC CIRCUITS SHOWING NK ${ }_{1}$ AND $\mathrm{CB}_{1}$ RECEPTORS IN NTS (NUCLEUS TRACTUS SOLITARIUS), NODOSE GANGLION, MYENTRIC PLEXUS AND SUBMUCOSAL PLEXUS

Two well-investigated endocannabinoids are recognized, $\mathrm{N}$-arachidonoylethanolamide (also called anandamide) and 2-arachidonoylglycerol (2-AG), in both the brain and the gut. Following their cellular reuptake, the metabolism of anandamide is is carried out fatty acid amide hydrolase (FAAH) and 2-AG metabolised by monoacylglycerol lipase (MAGL). To some extent 2-AGis also metabolized by other hydrolases, as well as by FAAH. 
Pharmacokinetics: It is readily absorbed after oral administration. It undergoes extensive first-pass metabolism with limited systemic bioavailability after single doses Metabolites are excreted primarily via the biliary-fecal route.

\section{Adverse effects:}

- Euphoria or dysphoria, sedation and hallucinations

- Abrupt withdrawal leads o withdrawal syndrome (restless, insomnia and irritability)

- Autonomic effects (sympathetic) in the form of tachycardia, palpitation, conjunctival injection, and orthostatic hypotension.

Use: It is used for the prevention of chemotherapyinduced nausea and vomiting.

Antiemetics in Cancer Chemotherepy: Antiemetic agents are also prescribed in cancer chemotherapy. Some of them are described below:

1) Phenothiazines: It is used to overcome the problem of apomorphine induced nausea and vomiting. Phenothiazines have gone through randomized conditions to check antiemetic effectiveness in various chemotherapeutic regimens. Its derivatives are most frequently used to prevent emesis in cancer chemotherapy. Toxicity usually consists of sedation, with occasional extra pyramidal and "paradoxical" reactions ${ }^{4,15}$.

2) Cannabinoids: It includes tetrahydrocannabinol (THC); it is the psychoactive substance of cannabis and has antiemetic properties. THC and synthetic cannabinoids (nabilone, levonantradol) have been studied in randomized clinical trials. The side effects of THC are sedation, hypotension, dizziness, and a psychotropic "high". The psychogenic reactions have caused a decreased acceptance of cannabinoids ${ }^{14,15}$.

3) Butyrophenones: Droperidol and haloperidol are effective antiemetic. Butyrophenones such as haloperidol also have antiemetic activity mediated by antidopaminergic action on the CTZ of the area postrema. Several clinical studies have shown the high antiemetic qualities and a very low incidence of side effects including sedation and extra pyramidal reactions ${ }^{15,16}$.

4) Benzamides: Among benzamides, metoclopramide, alizapride, and benzquinamide are also widely used as antiemetic. They exert their antiemetic action by blocking dopamine receptors in the CTZ and the gastrointestinal tract. At higher doses, metoclopramide acts as a 5-HT3 receptor antagonist; however, its antiemetic efficacy is less than that observed with 5-HT3 receptor antagonists. Most frequent side effect of benzamides is sedation. Occasionally dystonic reactions and akathisia have been reported ${ }^{15,16}$.

5) Corticosteroids: Corticosteroids such as dexamethasone or methylprednisolone have been used in most of clinical trials. They work to suppress CINV by limiting peritumoral inflammation and prostaglandin production. Corticosteroids are the most frequently used antiemetics and are given in combination with 5HT3 receptor antagonists. Interactions with the antitumor efficacy of the chemotherapeutic drugs were not noted. Corticosteroids are effective antiemetic with a low degree of toxicity ${ }^{13,15,16}$.

\section{Recent Advances in Antiemetics:}

Palonosetron: Palonosetron is a novel $5-\mathrm{HT}_{3}$ receptor antagonist; it has a binding affinity for the 5-HT3 receptor. It has an elimination half-life of $40 \mathrm{~h}$ longer than that of ondansetron (4-6 h), granisetron (5-8 h), tropisetron $(7 \mathrm{~h})$ and dolasetron $(7 \mathrm{~h})$. In addition to this, palonosetron exhibits allosteric interactions that trigger 5-HT3 receptor internalisation. Compared with currently available 5-HT3-RAs, palonosetron provides a better control over CINV. Primarily it is metabolized by CYP2D6 and to a lesser extent by CYP3A and CYP1A2 also. When administered in combination with dexamethasone in the same study, a subgroup analysis revealed that palonosetron was reported to be more effective than ondansetron plus dexamethasone. The combination of palonosetron and dexamethasone has also been evaluated in patients receiving multiple-day cisplatin based chemotherapy; response rates were high in both the acute and delayed phases ${ }^{16,17}$. 
Aprepitant: Aprepitant is the most commonly used antagonist among all the NK1 receptor antagonists that differentiate in site of action from 5-HT3 antagonists which appear to work primarily at a peripheral site. To exert its antiemetic effect, it requires entry into the central nervous system. It is capable to inhibit both acute and delayed emesis induced by cytotoxic chemotherapeutic agent such as cisplatin by blocking substance $\mathrm{P}$ which also target receptors in the neurons. Metabolization of aprepitant is carried out primarily by CYP3A4 and minor metabolism by CYP1A2 and CYP2C19. The half-life ranged from 9 to 13 hours approximately ${ }^{5,17,18}$.

TABLE 1: SOME MARKETED ANTIEMETICS PREPARATIONS ${ }^{20,21}$

\begin{tabular}{|c|c|c|c|}
\hline Generic \& Class & Brand & Form(s) & Company \\
\hline \multicolumn{4}{|l|}{ ANTICHOLINERICS } \\
\hline Scopolamine & Transderm SCOP & Transdermal Patch & Novartis Cons. \\
\hline ANTIHISTAMINES & Antivert & Tabs & Pfizer \\
\hline Meclizine & Zentrip & Orally-disintegrating thin strips & Sato \\
\hline Diphenhydramine & Benadryl & IV or IM Inj. & Pfizer \\
\hline \multicolumn{4}{|l|}{ CANNABINOIDS } \\
\hline Dronabinol & Marinol & Caps & Unimed \\
\hline Nabilone & Cesamet & Caps & Valeant \\
\hline \multicolumn{4}{|c|}{ 5-HT ${ }_{3}$ RECEPTOR ANTAGONIST } \\
\hline Dolasetron & Anzemet & IV Inj. & Sanofi-Aventis \\
\hline Granisetron & Sancuso & Transdermal patch, Tabs & ProStrakan \\
\hline Olandansetron & Zofran & Tabs (ODT) & GSK \\
\hline Ondansetron & Zuplenz & Oral Soluble Films & Strativa \\
\hline Palonosetron & Aloxi & IV Inj. & Eisai \\
\hline \multicolumn{4}{|l|}{ PHENOTHIAZINES } \\
\hline Chlorpromazine & Various & Tabs, Inj. & Various \\
\hline \multicolumn{4}{|l|}{ SUBSTITUTED BENZAMIDES } \\
\hline Metoclopramide & Metozolv ODT & Orally-disintegrating Tabs & Salix \\
\hline Trimethobenzamide & Tigan & IM Inj., Caps & King \\
\hline \multicolumn{4}{|c|}{ SUBSTANCE P/NEUROKININ RECEPTOR ANTAGONIST 1} \\
\hline Aprepitant & Emend Injection & IV Inj. & Merck \\
\hline
\end{tabular}

CONCLUSION: It can be concluded that antiemetics can be used alone or in combination depending upon the total emetic potential of the chemotherapeutic regimen. 5-HT3 receptor antagonists are highly effective antiemetic drug that when used in combination with dexamethasone represents the most efficacious regimens for the prevention of acute emesis induced by cisplatin and by moderately emetogenic chemotherapy.
Fosaprepitant: Fosaprepitant (dimeglumine) is a water-soluble phosphoryl prodrug for aprepitant. After intravenous administration it is converted into aprepitant within 30 minutes by the action of ubiquitous phosphatases. Equivalence studies reveal that $125 \mathrm{mg}$ orally administrated aprepitant being equivalent to $115 \mathrm{mg}$ fosaprepitant. In phase I and II trials, fosaprepitant shows efficacy, but aprepitant is utilized by most of the randomized efficacy studies ${ }^{6}$.

Casopitant: It is a novel NK1 antagonist whose marketed preparation is scheduled and have completed phase II and phase III trials. It can be given orally or intravenously ${ }^{6,19}$. 


\section{REFERENCES:}

1. Tripathi KD: "Essentials of medical pharmacology", Jaypee Brothers Medical Publishers, New Delhi, Edition $6^{\text {th }}, 2009: 640-647$.

2. Morrow GR, "Methodology and assessment in clinical antiemetic research: a meta- analysis of outcome parameters", Br. J. Cancer 1992; 66 (19): S38-S41.

3. Grunberg SM, Noonan K, "Perspectives on Recent Clinical Practice Guideline Updates for the Management of Chemotherapy-Induced Nausea and Vomiting", The Official Publication of the Association for Value-Based Cancer Care 2012; 3(2):4-6.

4. Norred CL, "Antiemetic Prophylaxis: Pharmacology and Therapeutics", The American Association of Nurse Anesthetists Journal 2003; 71(2): 133-140.

5. Girish C, Manikandan S, "Aprepitant: A substance P antagonist for chemotherapy induced nausea and vomiting", Indian Journal of Cancer 2007; 44(1): 25-30.

6. Dewan $P$, Singhal $S$, and Harit D, "Management of Chemotherapy-Induced Nausea and Vomiting", Indian Pediatrics 2010; 47: 149-155.

7. Grunberg SM, Ireland A et al "Epidemiology of Chemotherapy Induced Nausea and Vomiting", Advanced Studies in Nursing 2005; 3(1): 9-15.

8. Mowanie M B, AlYemni D, AlGhamdi S et al, "Serotonin receptors antagonists as antiemetic" Department of Pharmacology Collage of medicine King Saud University, 1-88.

9. Feyer $\mathrm{P}$, Jordan $\mathrm{K}$, "Update and new trends in antiemetic therapy: the continuing need for novel therapies", Annals of Oncology 2010; doi:10.1093/annonc/mdq600:1-9.
10. Kris MG, Radford J E, Pizzo BA et al. "Use of an NK1 receptor antagonist to prevent delayed emesis after cisplatin" J Natl Cancer Inst 1997; 89: 817-818.

11. Bisht M, Bist S S, "An update on pharmacotherapy of vertigo", J. Chem. \& Pharm. Res. 2010; 2(3):381-386.

12. Abell TL, Bernstein RK, et al, "Treatment of gastroparesis: a multidisciplinary clinical review", Neurogastroenterol Motil 2006; 18: 263-283.

13. Feeney K, "Chemotherapy induced nausea and vomiting", Australian Family Physician 2007; 36(9): 702-705.

14. Darmani NA, "Mechanisms of Broad-Spectrum Antiemetic Efficacy of Cannabinoids against Chemotherapy-Induced Acute and Delayed Vomiting", Pharmaceuticals 2010; 3: 2930-2955.

15. Higi M, "Antiemetics in Cancer Chemotheraphy", Haematology and Blood Transfusion 1985; 29: 143-144.

16. Navari RM, "Overview of the updated antiemetic guidelines for chemotheraphy - induced nausea and vomiting", Community Oncology 2007; 4(4): 3-11.

17. Roila F \& Fatigoni S, "New Antiemetic Drugs", Annals of Oncology 2006; 17(2): 96-100.

18. Antonarakis ES, Hain RDW. Nausea and vomiting associated with cancer chemotherapy: drug management in theory and practice. Arch Dis Child 2004; 89: 877-880.

19. Lohr L. "Chemotherapy-induced nausea and vomiting", Cancer J. 2008 ; 4: 85-93.

20. Ashish P, Haroliya MS, Pathan J K, Shruti S, " Formulation of Mouth Dissolving Tablet ", Int. J. Pharm. \& Clinical Science 2011; 1(1): 1-8.

21. Web link of Antiemetic Medications - MPR.htm.

How to cite this article:

Kumar A and Kumar A: Antiemetics: A Review. Int J Pharm Sci Res., 2013, 4(1); 113-123. 